\title{
Obtenção e caracterização química e nutricional de diferentes concentrados de caseína
}

\section{Obtention and chemical and nutritional characterization of different bovine casein concentrates}

Janesca Alban ROMAN ${ }^{1}$

Valdemiro Carlos SGARBIERI ${ }^{1}$

\section{R E S U M O}

\section{Objetivo}

O objetivo deste trabalho foi avaliar a composição centesimal, o perfil de aminoácidos e as características nutricionais de três concentrados de caseína, obtidos do leite bovino por diferentes processos.

\section{Métodos}

Os concentrados de caseína foram analisados pelos seguintes processos: uma caseína comercial, obtida por precipitação ácida seguida de neutralização; caseína obtida pela coagulação enzimática; caseína micelar obtida, respectivamente, pelos processos de microfiltração e diafiltração em membrana. A composição centesimal foi determinada por meio de procedimentos descritos no manual Official Methods of Analysis. O perfil de aminoácidos foi determinado após hidrólise ácida da proteína $\left(\mathrm{HCl} 6 \mathrm{~N}, 105^{\circ} \mathrm{C}, 22 \mathrm{~h}\right)$ em auto-analisador de aminoácidos, dotado de coluna de troca catiônica e reação pós-coluna com ninidrina. Os perfis de aminoácidos essenciais dos diferentes concentrados de caseína foram comparados e estão de acordo com o padrão Food and Agriculture Organization/World Health Organization, para crianças de 2 a 5 anos de idade. O valor nutritivo foi determinado em ratos da linhagem Wistar, recém desmamados, por meio dos índices, digestibilidade aparente da proteína, quociente de eficiência líquida da proteína e quociente de eficiência protéica operacional.

\section{Resultados}

A caseína comercial apresentou maior concentração de proteína $(92,0 \%)$, que a caseína micelar $(86,0 \%)$ e o coágulo de caseína (72,0\%). Os animais nas dietas com as diferentes fontes de proteína, não apresentaram

\footnotetext{
$\overline{1}$ Faculdade de Tecnologia de Alimentos, Departamento de Alimentos e Nutrição, Universidade Estadual de Campinas. Rua Monteiro Lobato, 80, 13083-970, Campinas, SP, Brasil. Correspondência para/Correspondence to: V.C. SGARBIERI. E-mail: <sgarb@fea.unicamp.br>.
} 
diferenças significativas quanto ao ganho de peso e ingestão de dieta. Maior digestibilidade $(93,8 \%)$ foi verificada na caseína comercial, comparada à dos outros dois concentrados $(91,0 \%)$.

\section{Conclusão}

Os concentrados de caseína apresentaram diferenças quanto à composição centesimal, sendo a caseína comercial superior na concentração protéica. O coágulo de caseína apresentou resultados inferiores aos demais concentrados, quanto aos índices quociente de eficiência líquida da proteína e quociente de eficiência protéica operacional.

Termos de indexação: coágulo de caseína, leite, micelas de caseína, valor nutritivo.

\section{A B S T R A C T}

\section{Objetive}

The objective of the present work was to evaluate the centesimal composition, the amino acid profile and the the composition and nutritive value of three casein concentrates, obtained by different methods.

\section{Methods}

The casein concentrates were analysed according to the following methods: a commercial casein obtained by acid precipitation (pl) followed by neutralization; an enzyme coagulated casein obtained by rennet coagulation; and a casein micelles concentrate obtained by microlfiltration and diafiltration. The Centesimal composition was determined by the procedures described in the manual Official Methods of Analysis. The amino acid profiles were determined after the protein acid hydrolysis $\left(\mathrm{HCl} 6 \mathrm{~N}, 105^{\circ} \mathrm{C}, 22 \mathrm{~h}\right)$ in an amino acid autoanalyzer by cation exchange chromatography and post-column ninhydrin reaction. The essential amino acids were in accordance with Food and Agriculture Organization/World Health Organization recommendation for children 2 to 5 years of age. The nutritive value was determined on 21-day old rats of the Wistar strain through apparent net protein ratio, and protein efficiency ratio operational.

\section{Results}

Commercial casein presented higher protein concentration (92.0\%) than micellar casein (86.0\%) and casein clot (72.0\%). The animals in the various protein diets did not show significant differences as to body weight gain and diet consumption. The highest digestibility was that of commercial casein (93.8\%), compared to the other two concentrates (91.0\%).

\section{Conclusion}

The casein concentrates showed differences related to the centesimal composition, since the commercial casein presented a higher protein concentration. The casein clot was inferior to the other protein concentrates regarding net protein ratio and protein efficiency ratio operational.

Indexing terms: coagulated casein, milk, casein micelles, nutritive value.

\section{N T R O D U Ç Ã O}

O leite constitui uma das principais fontes de proteínas na alimentação de animais jovens e de humanos de todas as idades. Pode ser considerado o alimento mais completo da natureza e o único que satisfaz as necessidades dos recém-nascidos ${ }^{1}$.

As proteínas do leite compreendem duas frações principais: caseínas, que se apresentam 
principalmente no estado de partículas coloidais, (micelas) e proteínas do soro, que estão em solução 2,3. O leite bovino tem um conteúdo de proteína, expresso como \% N x 6,38, de 30-35 g/ litro. Ao redor de $78 \%$ destas proteínas são caseínas, organizadas na forma de micelas constituídas por $92 \%$ de proteínas e $8 \%$ de sais inorgânicos, principalmente fosfato de cálcio ${ }^{1}$.

As caseínas podem ser separadas das proteínas do soro principalmente por dois processos, precipitação no $\mathrm{pH}$ isoelétrico $(\mathrm{pH} 4,6$; $20^{\circ} \mathrm{C}$ ) e coagulação pela ação da enzima quimosina - pepsina (coalho comercial), no processamento industrial de fabricação de queijos ${ }^{4}$. Dois tipos básicos de caseína são produzidos na indústria, a caseína ácida e a de coalho que possuem essas denominações em função dos agentes coagulantes envolvidos ${ }^{5}$.

A caseína comercial, produzida por meio da precipitação ácida, é uma das principais proteínas com funcionalidade tecnológica em alimentos. Ela apresenta propriedades que não podem ser substituídas por outras proteínas em certas aplicações e vem sendo produzida há cerca de 70 anos $^{6}$. Caseínas e caseinatos são comumente utilizados na formulação de produtos cárneos ${ }^{7}$, produtos lácteos, produtos de panificação ${ }^{8}$, chocolates e confeitos, coberturas comestíveis, bebidas lácteas e achocolatados, salgadinhos e snacks ${ }^{9}$, filmes comestíveis e impermeabilizantes ${ }^{10}$.

Os métodos tradicionais de fabricação de caseína promovem alterações químicas irreversíveis na estrutura da micela de caseína, por meio da acidificação ou modificação enzimática, a fim de facilitar a separação das proteínas coaguladas dos constituintes do soro ${ }^{11}$.

O leite desnatado pode ser separado em frações ricas de caseína e de proteínas do soro, usando-se membranas cerâmicas ${ }^{12}$. A principal vantagem da separação por membranas é a de ser o processo termicamente suave e puramente mecânico. Isto significa que o processo não tem um impacto negativo nas propriedades funcionais e nutricionais do produto ${ }^{13-16}$
O objetivo deste trabalho foi avaliar dois concentrados de caseína, obtidos do leite bovino por diferentes processos: caseína obtida pela coagulação enzimática (COC), caseína micelar obtida pelo processo combinado de microfiltração/diafiltração em membrana, e verificar as suas diferenças quanto à composição centesimal, ao perfil de aminoácidos e ao perfil nutricional comparados à caseína comercial.

\section{ATERIALE MÉTODOS}

Leite tipo $B$, desnatado e pasteurizado $\left(72^{\circ} \mathrm{C}\right.$, 20s) foi obtido da Cooperativa dos Produtores de Leite da Região de Campinas, Jaguariúna, SP. Todo o processamento foi realizado na planta piloto do Centro de Tecnologia de Laticínios (Tecnolat), do Instituto de Tecnologia de Alimentos (Ital).

Na produção de caseína pelo processo de coagulação enzimática, o leite bovino foi homogeneizado e aquecido entre $30-35^{\circ} \mathrm{C}$. Adicionou-se o coalho, contendo renina e pepsina $(30 \mathrm{~mL} / 100 \mathrm{~L}$ de leite), e uma solução de cloreto de cálcio a $50 \%$ ( $25 \mathrm{~mL} / 100 \mathrm{~L}$ de leite), deixando-se em repouso por aproximadamente 40-60 minutos para coagulação. À medida que as micelas de caseína se desintegravam, formava-se o coágulo, ou seja, um gel mole, tri-dimensional de caseína, que ocupava o mesmo volume original do leite no tanque.

Em seguida, o coágulo foi cortado em pequenos cubos por meio de uma lira (horizontal e vertical com $1 \mathrm{~cm}$ de espaçamento entre os fios) e a massa foi agitada por meio de uma pá, de modo a facilitar a dessoragem. Este processo provocava a contração do gel e, conseqüentemente, expulsão da água e constituintes solúveis do leite do interior dos cubos, para que, depois de aproximadamente 20 minutos, o coágulo estivesse completamente dividido em grãos finos.

O coágulo obtido após separação do soro por filtração, foi lavado com água e triturado em presença de solução alcalina para obter suspensão 
homogênea em pH 7,0. Essa suspensão (15\% de sólidos) foi pré-aquecida a $60-70^{\circ} \mathrm{C}$, para a secagem em spray dryer, com temperatura de $210^{\circ} \mathrm{C}$ na entrada e cerca de $80^{\circ} \mathrm{C}$ na saída do spray, com uma vazão de 40 litros por hora. 0 material líquido, soro, foi drenado, ultrafiltrado (concentrado) e diafiltrado, para obtenção de concentrado protéico de soro e permeado (Figura 1).

Na produção de micelas de caseína (MC), a fração contendo as micelas foi obtida pelos processos de microfiltração e diafiltração, respectivamente em membrana polimérica (WGMKock Membrane Systems) e membrana cerâmica ${ }^{14}$ (Membralox ${ }^{\circledR}$ - Societé des Ceramiques Techniques). O leite foi concentrado a um quarto de seu volume inicial, fator de concentração quatro $(F C=4)$ e, em seguida, diafiltrado com água pura equivalente a quatro volumes de retentado (quatro ciclos). As condições experimentais foram temperatura fixa de $50^{\circ} \mathrm{C}$ e velocidade tangencial $6,1 \mathrm{~m} / \mathrm{s}$, determinadas mediante otimização deste processo, conforme Ferreira ${ }^{13}$. Após fracionamento e concentração, os materiais foram desidratados por liofilização.

\section{Métodos analíticos e biológicos}

Os teores de proteína $(N \times 6,38)$, umidade e cinzas foram determinados de acordo com os procedimentos descritos no manual da Association of Official Analytical Chemists ${ }^{17}$. Lipídios totais foram determinados pelo método descrito por Bligh \& Dyer ${ }^{18}$; teor de cálcio pelos procedimentos descritos no manual da Association of Official Analytical Chemists; e o conteúdo de carboidratos foi calculado por diferença entre $100 \%$ e a soma dos demais macronutrientes.

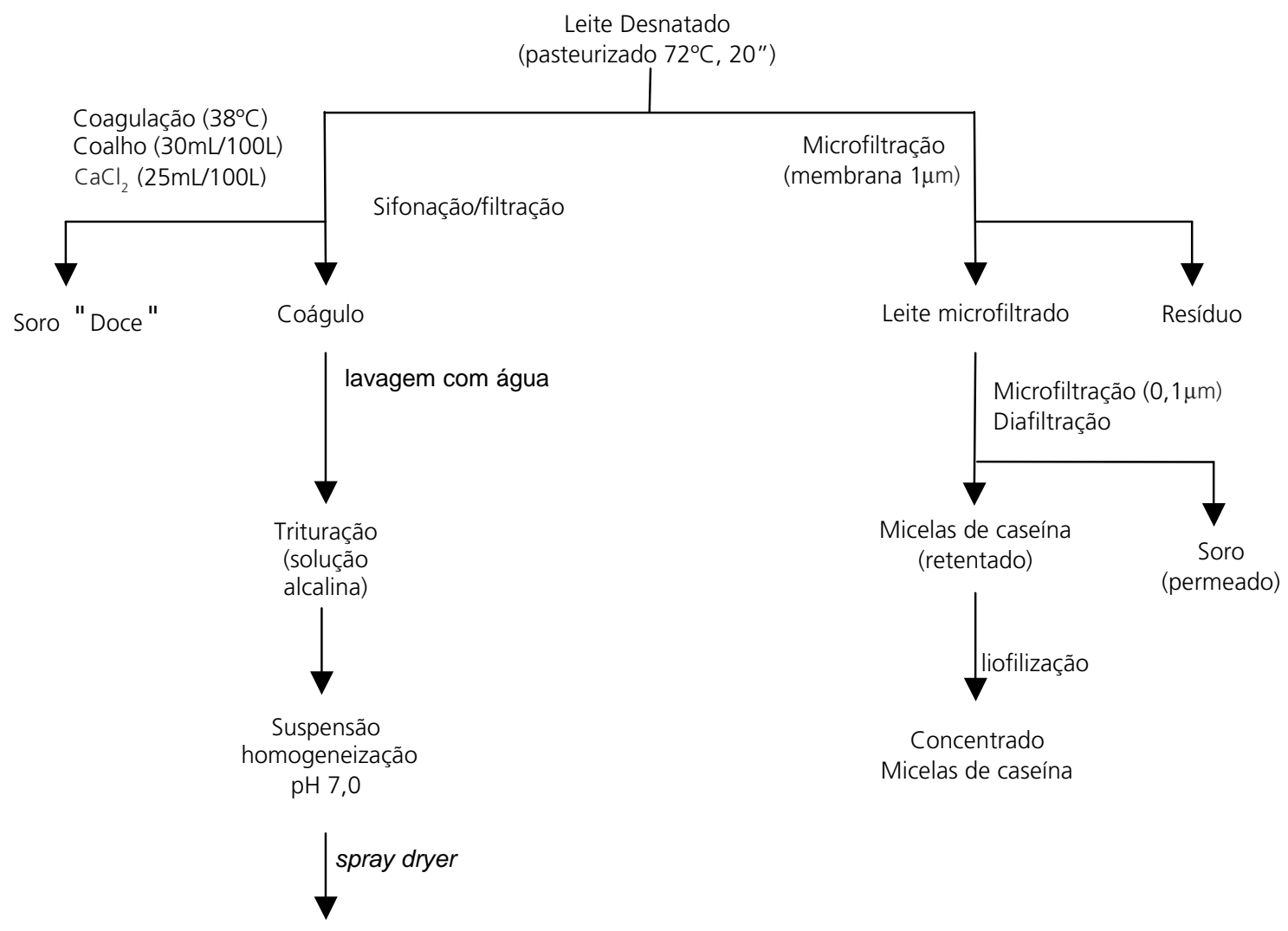

Figura 1. Obtenção do coágulo de caseína desidratado (COC) por meio do processo de coagulação enzimática e das micelas de caseína por microfiltração seguido de diafiltração, a partir do leite bovino. 
A determinação de aminoácidos foi feita após hidrólise ácida $\left(\mathrm{HCl} 6 \mathrm{~N}, 110^{\circ} \mathrm{C}, 22 \mathrm{~h}\right)$ em analisador de aminoácidos (Dionex Dx-300), por separação em coluna (HPLC) de troca catiônica, seguida de reação colorimétrica pós-coluna com ninidrina. A quantificação de cada aminoácido foi feita com base em uma mistura-padrão de aminoácidos marca Pierce (EUA). O aminoácido triptofano, que é destruído durante a hidrólise ácida, foi quantificado segundo Spies ${ }^{20}$. O escore químico de aminoácidos essenciais (EAE) foi determinado relacionando-se a concentração de cada um dos aminoácidos essenciais das frações protéicas em estudo, com os aminoácidos do padrão de referência da Food and Agriculture Organization ${ }^{21}$, de acordo com a metodologia de Henley \& Kuster ${ }^{22}$.

O valor nutritivo da caseína coagulada (COC) e da caseína micelar (CM), obtidas do leite bovino, foi estudado comparativamente à caseína comercial, por meio da dieta recomendada pelo American Institute of Nutritition (AIN-93G) para ratos em crescimento, exceto pela concentração de proteína usada, 10\% (p/p). As misturas de sais, contendo os elementos minerais (AIN-93G-MX) e mistura vitamínica (AIN-93-VX), também recomendadas pelo AIN, e descritas por Reeves et al. ${ }^{23}$, foram usadas no preparo das dietas.

Para a realização do ensaio foram preparadas quatro dietas utilizando diferentes fontes protéicas: 1) dieta padrão, de caseína comercial (CC), procedência M. Cassab (São Paulo); 2) dieta contendo como única fonte de proteína, o coágulo de caseína (COC); 3) dieta contendo como única fonte de proteína a caseína micelar (CM) e 4) dieta, aprotéica (APRO), ou seja, isenta de proteínas.

Foram utilizados, para o experimento, 32 ratos machos da linhagem Wistar livres de patógenos específicos (SPF), recém-desmamados, provenientes do Centro de Bioterismo (CEMIB) da Universidade Estadual de Campinas (Unicamp).

Os animais, com 21 dias de idade no início do experimento, foram distribuídos em 4 grupos de 8 ratos, os quais, alojados em gaiolas individuais contendo dieta e água ad libitum, foram mantidos no laboratório de experimentação a $22 \pm 2^{\circ} \mathrm{C}$, com períodos alternados de claro e escuro de 12 horas.

Todos os animais foram pesados antes do início do experimento, e uma tabela com ordem crescente de peso foi elaborada. Os grupos mantidos em dietas experimentais foram selecionados, tomando-se um animal de menor peso e um animal de maior peso, até completar o grupo com oito animais. O peso médio dos animais em cada grupo foi de $61,3 \pm 10,82 \mathrm{~g}$ (média \pm desvio-padrão).

O valor nutritivo da proteína foi estimado por meio dos índices de quociente de eficiência líquida da proteína (NPR), quociente de eficiência protéica operacional (PERop) e digestibilidade verdadeira da proteína (Dv), segundo metodologia descrita por Sgarbieri24. A metodologia convencional recomenda ensaio de quatro semanas para o PER. Portanto, neste ensaio, realizado com apenas três semanas, O PER deve ser interpretado como operacional (PERop). O escore químico, corrigido pela digestibilidade verdadeira (PDCAAS), foi determinado segundo a metodologia de Henley \& Kuster22, multiplicando-se o escore de aminoácidos essenciais, pela digestibilidade verdadeira da proteína $(P D C A A S=E A E \times D v)$.

Todos os resultados foram analisados por meio da análise de variância (ANOVA) e as diferenças significativas entre as médias $(p<0,05)$, pelo teste de Tukey ${ }^{25}$, utilizando-se o programa Statística: Basic Statistics and Tables.

\section{RESULTADOSE DISCUSSÃO}

Quanto à composição centesimal, o componente que aparece em maior concentração nas frações de caseína obtidas por diferentes processos, foi proteína (Tabela 1), sendo que a caseína comercial utilizada, apresentou uma maior concentração de proteína, significativamente superior à caseína micelar e ao coágulo. 
Tabela 1. Composição centesimal e determinação de cálcio do coágulo de caseína, caseína comercial e caseína micelar, todos em base seca.

\begin{tabular}{|c|c|c|c|c|c|c|}
\hline \multirow{2}{*}{ Componentes ( $\mathrm{g} / 100 \mathrm{~g}$ ) } & \multicolumn{2}{|c|}{ Caseína comercial } & \multicolumn{2}{|c|}{ Coágulo de caseína } & \multicolumn{2}{|c|}{ Caseína micelas } \\
\hline & M & $\mathrm{DP}$ & M & DP & M & $\mathrm{DP}$ \\
\hline Proteínas (N x 6,38) & 91,98 & $\pm 0,53^{a}$ & $72,36 \pm$ & $0,21^{c}$ & $86,14 \pm$ & $0,39^{\mathbf{b}}$ \\
\hline Cinzas & 2,41 & $\pm 0,02^{c}$ & $9,33 \pm$ & $0,09^{a}$ & $8,44 \pm$ & $0,02^{b}$ \\
\hline Lipídios & 2,26 & $\pm 0,05^{c}$ & $3,12 \pm$ & $0,03^{\mathbf{b}}$ & $4,30 \pm$ & $0,06^{\mathrm{a}}$ \\
\hline Carboidrato* & 3,35 & & 15,19 & & 1,12 & \\
\hline Cálcio (mg/100g) & 233,00 & $\pm 3,00^{\mathbf{b}}$ & $2653,00 \pm$ & $08,00^{\mathbf{b}}$ & $2627,00 \pm$ & $67,00^{\mathrm{a}}$ \\
\hline
\end{tabular}

* Carboidrato $=100$ - (proteína + lipídios totais + cinzas). Resultados são média de 3 determinações analíticas \pm desvio-padrão. Letra minúscula diferente (linha) indica diferença estatística pelo teste de Tukey $(p<0,05)$.

Tabela 2. Valores obtidos para os aminoácidos essenciais dos produtos, caseína comercial, coágulo de caseína e caseína micelar tendo por base o padrão de referência da $\mathrm{FAO} \mathrm{NHO}^{21}$

\begin{tabular}{lcccr}
\hline Aminoácidos (g/100g de proteína) & Padrão1 (FAOMHO) & Caseína comercial & Coágulo de caseína & Caseína micelas \\
\hline Treonina & 3,40 & 5,29 & 4,08 & 4,62 \\
Metionina + Cistina & 2,50 & 4,03 & 3,71 & 3,10 \\
Valina & 3,50 & 7,55 & 6,55 & 6,38 \\
Leucina & 6,60 & 11,99 & 11,03 & 10,30 \\
Isoleucina & 2,80 & 5,56 & 4,75 & 4,95 \\
Fenilalanina + Tirosina & 6,30 & 13,51 & 8,18 & 8,05 \\
Lisina & 5,80 & 9,06 & 8,08 & 3,03 \\
Histidina & 1,90 & 3,51 & 3,36 & 1,43 \\
Triptofano & 1,10 & 1,17 & 1,44 & 1,00 \\
\hline EAE* & - & 1,00 & 1,00 & 91,12 \\
PDCAAS* & - & 93,78 & 91,23 & \\
\hline
\end{tabular}

${ }^{1}$ Recomendações para crianças na idade de 2-5 anos. *EAE= Escore químico de aminoácidos essenciais, **PDCCAS= Escore químico corrigido pela digestibilidade verdadeira.

As caseínas, segundo Fox \& McSweeney ${ }^{26}$, têm um alto conteúdo (35\%-45\%) de aminoácidos apolares (Val, Leu, lle, Phe, Try, Pro) e um baixo conteúdo de aminoácidos sulfurados, os quais limitam seu valor biológico e nutritivo. No entanto (Tabela 2), o conteúdo de aminoácidos essenciais, em todas as amostras estudadas, satisfizeram aos requerimentos do padrão de referência da Food and Agriculture Organization.

O PDCAAS indica a proporção em que determinada fonte protéica é utilizada pelo organismo, de acordo com o padrão utilizado. Como o escore químico de aminoácidos essenciais está de acordo com o padrão da Food and
Agriculture Organization ${ }^{21}$, observa-se que o valor do PDCAAS foi igual ao da digestibilidade verdadeira da proteína (PERop), sendo que a caseína comercial apresentou um valor superior $(93,78 \%)$ aos da caseína coagulada e da caseína micelar.

A caracterização nutricional, tanto da caseína coagulada quanto das micelas de caseína, foi feita com base na composição de aminoácidos, no escore químico de aminoácidos essenciais e na avaliação nutricional em ratos.

No ensaio com animais foram determinados digestibilidade verdadeira (Dv), quociente de eficiência protéica (PERop) e quociente de 
eficiência líquida da proteína (NPR), tendo como referência a caseína comercial. As Tabelas 3 e 4 mostram alguns parâmetros que caracterizam o valor nutritivo das proteínas da CC, COC e CM. Na Tabela 3, mostram-se os dados referentes à ingestão de dieta, ingestão de proteína, ganho de peso, PERop e NPR. Na Tabela 4 estão representados os valores obtidos de digestibilidade verdadeira, nitrogênio ingerido e nitrogênio fecal. Os resultados indicados na Tabela 3, mostraram que não houve diferença significativa $(p>0,05)$ na ingestão da dieta, e no ganho de peso entre os grupos de animais, mantidos em diferentes preparações de caseína.

Embora a composição em aminoácidos tenha sido diferente para os concentrados protéicos que compunham as dietas, a análise estatística não mostrou diferença, quanto à variável crescimento, entre os vários tratamentos. Os animais em dietas protéicas, alimentados com diferentes concentrados de caseína, tiveram um aumento de peso médio de $84 \%$, após 21 dias de experimento, enquanto que os animais em dieta aprotéica, evidenciaram uma perda de peso média de $26 \%$ em relação ao peso médio inicial.

No tratamento com a caseína coagulada, observou-se uma ingestão significativamente mais elevada de proteína, que nos demais tratamentos. Quanto aos valores de PERop e NPR, as dietas contendo caseína comercial e caseína micelar não diferiram estatisticamente, tendo sido superiores à caseína coagulada. Friedman ${ }^{27}$, considera de alto valor nutritivo, proteínas com valor de PER acima de 2,0 .

Alguns fatores podem influenciar os valores de PER; dentre eles, a concentração lipídica e a concentração protéica da dieta. Elevadas concentrações de proteínas acrescentadas na dieta, acima de $15 \%$, elevam o consumo de proteína para fins energéticos, diminuindo a

Tabela 3. Valores obtidos da ingestão de dieta, ingestão de proteína, ganho de peso, quociente de eficiência protéica e quociente de eficiência líquida da proteína da caseína comercial, coágulo de caseína e caseína micelar.

\begin{tabular}{|c|c|c|c|c|c|c|c|c|c|c|}
\hline \multirow{2}{*}{ Fonte protéica } & \multicolumn{2}{|c|}{ Dieta ingerida (g) } & \multicolumn{2}{|c|}{ Proteína ingerida (g) } & \multicolumn{2}{|c|}{ Ganho de peso (g) } & \multicolumn{2}{|c|}{ PERop } & \multicolumn{2}{|c|}{ NPR } \\
\hline & $M$ & DP & $M$ & DP & $M$ & DP & $M$ & DP & $\mathrm{M}$ & DP \\
\hline Caseína comercial & 305,00 & $\pm 27,9$ & $34,04 \pm$ & $3,62^{b}$ & $114,58 \pm$ & $8,69^{b}$ & 3,36 & $\pm 0,19^{a}$ & 3,85 & $\pm 0,20^{a}$ \\
\hline Coágulo de & 332,57 & $\pm 16,8$ & $37,41 \pm$ & $1,90^{\mathrm{a}}$ & $114,69 \pm$ & $9,62^{a}$ & 3,06 & $\pm 0,15^{b}$ & 3,50 & $\pm 0,15^{b}$ \\
\hline Caseína micelar & 314,26 & $\pm 11,5$ & $35,45 \pm$ & $1,30^{\mathrm{b}}$ & $116,26 \pm$ & $6,45^{\mathrm{b}}$ & 3,28 & $\pm 0,18^{a}$ & 3,74 & $\pm 0,19^{a}$ \\
\hline
\end{tabular}

Resultados são média de 8 animais por tratamento \pm desvios-padrão. Médias seguidas por uma mesma letra (coluna) não diferem entre si, ao nível de $5 \%$ de probabilidade pelo teste de Tukey. PERop = quociente de eficiência protéica; NPR= quociente de eficiência líquida da proteína.

Tabela 4. Valores obtidos para digestibilidade verdadeira, nitrogênio ingerido e nitrogênio fecal para a caseína comercial, caseína coagulada, caseína micelar.

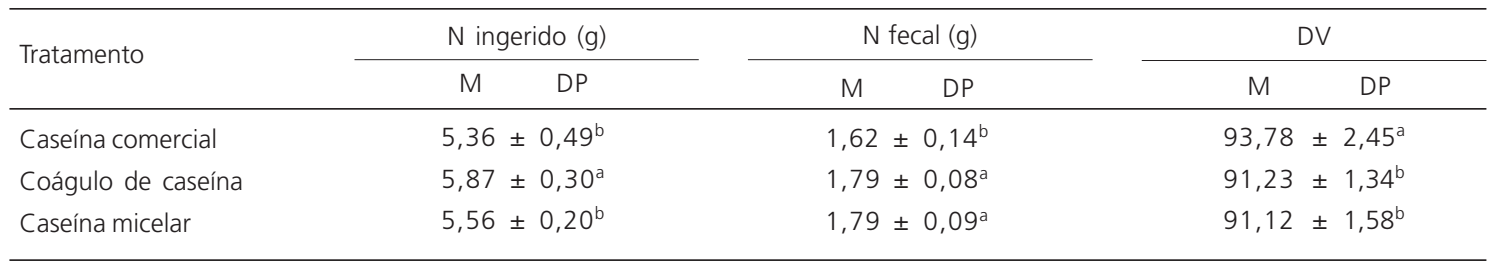

Resultados são média de 8 animais por tratamento \pm desvio-padrão. Médias seguidas por uma mesma letra (coluna) não diferem entre si, ao nível de $5 \%$ de probabilidade pelo teste de Tukey, N= Nitrogênio, Dv= digestibilidade verdadeira 
eficiência da proteína para a síntese de novas proteínas corpóreas.

Segundo Sgarbieri' ${ }^{1}$ a concentração de proteína ideal para análise do índice de PER, em que a mesma será utilizada preferencialmente para a síntese de proteínas corporais, está no intervalo de $10 \%$ a $12 \%$ para a proteína de alto valor nutritivo.

A digestibilidade verdadeira do coágulo de caseína e da caseína micelar, foi significativamente menor que a da caseína comercial. Essa menor digestibilidade do COC pode estar relacionada ao processo de obtenção e secagem; no caso, a caseína micelar pode estar relacionada à integridade da micela que possivelmente dificulta a ação das enzimas digestivas. Ao comparar os dados resultantes dos tratamentos, observa-se que os animais submetidos à dieta com coágulo de caseína, ingeriram quantidade significativamente superior de nitrogênio.

\section{O N CLUSÃ O}

Verificou-se que os concentrados de caseína estudados, caseína coagulada pela quimosina, caseína micelar e caseína comercial, apresentaram diferenças significativas quanto à composição centesimal, sendo o componente de maior concentração, a proteína, significativamente superior para a caseína comercial. Os teores de cálcio e de cinzas foram significativamente inferiores para a caseína comercial, quando comparados aos dos demais concentrados.

Nos vários tratamentos com os concentrados estudados, apesar das variações observadas na composição de aminoácidos, não se observou variação estatística significativa $(p>0,05)$ para o crescimento dos ratos; isto, devido ao fato de a composição atender às recomendações do padrão de referência da Food and Agriculture Organization/Wold Health Organization. Quanto ao PERop e ao NPR, observou-se que esses índices foram significativamente inferiores para a dieta com caseína coagulada, em relação aos demais tratamentos. O melhor resultado de digestibilidade (93,78\%) foi o da caseína comercial. Idêntico valor encontrado para o PDCAAS (93,79\%), foi significativamente superior ao encontrado nos tratamentos com as caseínas coagulada e micelar.

\section{A GRADECIMENTOS}

Os autores agradecem à FAPESP (Fundação de Amparo a Pesquisa de São Paulo) pelo suporte financeiro para esta pesquisa e pela bolsa concedida a Janesca Alban Roman.

\section{REFER Ê NCIAS}

1. Sgarbieri VC. Proteínas em alimentos protéicos: propriedades, degradações, modificações. São Paulo: Varela; 1996.

2. Davian C, Farnelart MH, Pierre A, Gouderanche H, Maubois JL. Rennet coagulation of skin milk and curd drainage: Effect of $\mathrm{pH}$, casein concentration, ionic strength and heat treatment. Le Lait. 2000. 80(4):397-415.

3. Gaucheron F, Le Graët Y, Briard V. Effect of sodium chloride addition on the mineral equilibrium of concentrated and acidified casein micelles. Milchwissenschaft. 2000: 55(2):82-6.

4. Wong DWS, Camirant WM, Pavlath AE. Structures and functionalities of milk proteins. Crit Rev Food Sci Nutr. 1996; 36(8):807-44.

5. Southward CR. Utilization of milk components. In: Modern dairy technology - advances in milk processing. New York: Elselvier; 1986. p.317-68.

6. Fox PF. The milk protein system. In: Fox PF, editor. Developments in dairy chemistry - 4. London: Elsevier; 1989. p.1-55.

7. Kinsella JE. Milk proteins: physico-chemical and functional properties. Rev Food Sci Nutr. 1984; 21 (2):197-262.

8. Giese J. Proteins as ingredients: types, functions, applications. Food Technol. 1994; 48(10):50-60.

9. Southward CR. Use of casein and caseinates. In: Fox PF, editor. Development in dairy chemistry. New York: Elselvier; 1989. p.173-224. 
10. Torres JA. Addible films and coating from proteins. In: Hettiarachechy NS, Ziegler GR, editors. Protein functionality in food systems. New York: Marcel Dekker; 1994. p.467-507, 519.

11. Smithers G. Value added milk protein products. Austr Biotechnol. 1991; 1(1):36-9.

12. Punidadas P, Rizvl SSH. Separation of milk proteins into fractions rich in casein or whey proteins by cross flow filtration. Food Res Inter. 1998; 31(4):265-72.

13. Ferreira CV. Influência da velocidade tangencial e da pressão transmembrana na obtenção de caseína por microfiltração [dissertação]. Campinas: Faculdade de Engenharia de Alimentos, Universidade Estadual de Campinas; 2001.

14. Osterland N. New developments in membrane processing. Proceedings of the 25th International Dairy Congress, Sep 21-24, Aarhus, Denmark, International Dairy Federation; 1988. p.30-1.

15. Boland M, MacGibbon A, Hill JP. Designer milks for the new millennium. Livestock Prod Sci. 2001; 56:117-22.

16. Creamer LK, Pearce LE, Hill JP, Roland MJ. Milk and dairy products in the 21st century. J Agric Food Chem. 2002; 50:(25)7187-93.

17. Association of Official Analytical Chemists. Official Methods of Analysis. 15th ed. Washington, DC; 1990.

18. Bligh EG, Dyer WJ. A rapid method of total lipid extraction and purification. Can Biochem Physiol. 1959; 37(8):911-7.
19. Association of Official Analytical Chemists. Official Methods of Analysis. 16th ed. Washington, DC; 1995.

20. Spies JR. Determination of tryptofan in proteins. Analyt Chem. 1967; 39(12):1412-5.

21. Food and Agriculture Organization of the United Nations. Report on a joint FAO/WHO Expert Consolation on Protein Quality Evaluation. Bethesda; 1990.

22. Henley EC, Kuster JM. Protein quality evaluation by protein digestibility-corrected amino scoring. Food Technol. 1994; 48(4):74-77.

23. Reeves PGPG, Nielsen FH, Fahey GN. AIN-93. Purified diets for laboratory rodents: Final report of the American Institute of Nutrition ad hoc Writing Committee on the formulation of the AIN-76. Rodent diet. Nutrition. 1993; 123:(11) 467-72.

24. Sgarbieri VC. Alimentação e nutrição: fator de saúde e desenvolvimento. São Paulo; Almed; 1987.

25. Gomes FP. Curso de estatística experimental. 10. ed. São Paulo: Nobel; 1982.

26. Fox PF, McSweeney PLH. Milk proteins. In: Dairy chemistry and biochemistry. London: Blackie Academic; 1998. p.147-238.

27. Friedman M. Nutritional value of proteins from different food sources. A review. J Agric Food Chem. 1996; 44(1):6-29.

Recebido para publicação em 9 de março de 2003 e aceito em 17 de junho de 2004 